\title{
Acute Dystonia Following a Switch in Treatment from Atomoxetine to Low-dose Aripiprazole
}

\author{
Ömer Başay ${ }^{1}$, Burge Kabukcu Basay ${ }^{1}$, Önder Öztürk, Zeki Yüncü ${ }^{1}$ \\ ${ }^{1}$ Department of Child and Adolescent Psychiatry, School of Medicine, Pamukkale University, Denizli, ${ }^{2}$ Department of Child and Adolescent \\ Psychiatry, School of Medicine, Ege University, Izmir, Turkey
}

\begin{abstract}
The present report describes the cases of a 17-year-old male patient and a 13-year-old female patient who developed acute dystonia following the administration of low-dose aripiprazole ( $5 \mathrm{mg} /$ day) after the cessation of atomoxetine treatment. Although aripiprazole-induced dystonia has been previously reported in the literature, it is rare, and most of these cases were associated with doses higher than $5 \mathrm{mg} /$ day. Furthermore, both of the patients in the present study discontinued atomoxetine prior to the initiation of aripiprazole treatment; thus, this report also discussed the possible mechanisms underlying the manifestation of dystonia from the perspective of neurotransmitter activity.
\end{abstract}

KEY WORDS: Aripiprazole; Atomoxetine; Dystonia.

\section{INTRODUCTION}

Aripiprazole is a third-generation atypical antipsychotic that acts as a dopamine-serotonin system stabilizer and effectively alleviates both the positive and negative symptoms of schizophrenia. This drug is associated with low rates of extrapyramidal symptoms (EPS), ${ }^{1-3)}$ as evidenced by the lack of significant differences in EPS between aripiprazole and placebo groups in adult studies. ${ }^{4)}$ Nevertheless, several case reports have documented the development of aripiprazole-induced dystonia in various populations. $^{5-7)}$ In children and adolescents, aripiprazole is commonly used for the treatment of bipolar disorder, schizophrenia, autism, tics, and disruptive behavior disorders. ${ }^{89}$ A review of aripiprazole use in children and adolescents found that EPS and akathisia occurred at rates of $8-28 \%,{ }^{10)}$ and a previous case report described a patient who dropped out of a study due to the manifestation of dystonia following treatment with a fixed dose of aripiprazole (25 mg/day). ${ }^{8}$

The development of acute dystonia following a treatment switch from psychotropic drugs that affect the dop-

\footnotetext{
Received: July 8, 2015 / Revised: September 10, 2015

Accepted: November 12, 2015

Address for correspondence: Burge Kabukcu Basay, MD Department of Child and Adolescent Psychiatry, School of Medicine, Pamukkale University, Denizli 20070, Turkey

Tel: +90-5325401413, Fax: +90-258-2134922

E-mail: burgekabukcu@yahoo.com
}

aminergic system to aripiprazole is noteworthy. McLaren et al. ${ }^{11)}$ reported the development of aripiprazole-induced acute dystonia in an 11-year-old male with attention deficit hyperactivity disorder (ADHD) and bipolar disorder following the discontinuation of a stimulant medication. In another case, novel-onset dystonia occurred in a 22-year-old schizophrenic patient after switching from olanzapine to aripiprazole. ${ }^{12)}$ These cases emphasize the importance of understanding the treatment environments of individual patients that are created by prior pharmacological regimens because aripiprazole, which is a partial dopamine agonist, is highly affected by dopaminergic tone in the surrounding milieu. ${ }^{13)}$ In light of this pharmacological feature, the present study describes two patients with ADHD who developed acute dystonia following treatment with low doses of aripiprazole that commenced immediately after the discontinuation of atomoxetine. Atomoxetine is a selective inhibitor of the noradrenaline transporter that increases extracellular concentrations of noradrenaline and dopamine in the prefrontal cortex (PFC). ${ }^{14)}$

The prior use of psychotropic agents was a common feature in the present cases, and one distinctive and interesting characteristic of these cases was the probable neurotransmitter-related changes caused by atomoxetine. The present article provides possible explanations for the manifestation of dystonia in these patients based on action within the dopamine system, which is a common pathway

(a) This is an Open-Access article distributed under the terms of the Creative Commons Attribution Non-Commercial License (http://creativecommons.org/licenses/by-nc/4.0) which permits unrestricted non-commercial use, distribution, and reproduction in any medium, provided the original work is properly cited. 
for atomoxetine and aripiprazole.

The ethical standards were followed and the patients and their parents gave written informed consent for the publication.

\section{CASE}

\section{Case 1}

A 17-year-old male was admitted to our child and adolescent psychiatry outpatient clinic with complaints of inattention, hyperactivity, aggression, and frequent involvement in physical fights. His clinical assessment suggested a diagnosis of combined type ADHD in conjunction with conduct disorder based on the criteria of the Diagnostic and Statistical Manual of Mental Disorders, 4th edition, text revision (DSM-IV-TR), ${ }^{15)}$ and as a result, the patient was initially prescribed atomoxetine $(0.5 \mathrm{mg} / \mathrm{kg})$. Because the patient's irritability increased when he was treated with a higher dose of atomoxetine $(1.2 \mathrm{mg} / \mathrm{kg}$ [60 mg/ day]), this drug was discontinued, and treatment with daily aripiprazole $(5 \mathrm{mg} / \mathrm{kg})$ commenced. Following the second dose of aripiprazole (approximately 36 hours after the last dose of atomoxetine), the patient was admitted to our emergency department with complaints of abrupt and painful involuntary contractions in his neck.

A neurological examination detected torticollis, but his laboratory findings were normal. A review of his medical history revealed that the patient was experiencing this event for the first time, he had not used any drugs other than aripiprazole, and he did not have a history of substance use or food intake that would indicate susceptibility to intoxication. Furthermore, mood disorders, psychosis, and anxiety disorders were ruled out and the patient did not have a significant personal or family history of head trauma or autoimmune disease. Subsequently, the patient was diagnosed with aripiprazole-induced acute dystonia according to the Naranjo Probability Scale, ${ }^{16)}$ and he was administered intramuscular biperiden ( $5 \mathrm{mg}$ ). The torticollis disappeared within minutes, and the use of aripiprazole was discontinued. The patient was prescribed bornaprine hydrochloride ( $2 \mathrm{mg}$, two times a day) and discharged from the hospital. During the patient's follow-up visit 2 days after he was released, his physical and neurological examinations were entirely normal.

\section{Case 2}

A 13-year-old female who had been diagnosed with ADHD and a mild intellectual disability according to the criteria of the DSM-IV-TR ${ }^{15)}$ was initially prescribed atomoxetine ( $80 \mathrm{mg} /$ day) to treat the ADHD. She was admitted to our outpatient polyclinic with complaints of increased sexual desire and behaviors, excessive talking, and poor sleep patterns. Due to her hypomanic symptoms, the atomoxetine treatment was discontinued, and aripiprazole $(5 \mathrm{mg} /$ day) treatment was initiated the same day. Approximately 5 hours after the first dose of aripiprazole (16 hours after the last atomoxetine dose), the patient was referred to the emergency service due to difficulties swallowing and contractions in and around her mouth.

The patient's neurological examination revealed facial asymmetry and reduced speech intelligibility but no other objective findings. Routine laboratory assessments and a cranial tomography were also normal. The patient had no significant personal or family history of head trauma, acute/chronic diseases, or susceptibility to intoxication. The patient was diagnosed with aripiprazole-induced acute dystonia, and she was administered intramuscular biperiden $(5 \mathrm{mg})$. The patient's complaints were ameliorated within minutes, and she was discharged with a prescription for oral biperiden ( $4 \mathrm{mg} /$ day). During the patient's follow-up visit 3 days after she was released, her physical and neurological examinations were entirely normal. The patient began risperidone treatment, and no similar findings were detected during her subsequent control visits.

\section{DISCUSSION}

Aripiprazole has a low EPS profile that is attributed to its partial agonist activity at the dopamine D2 and serotonin 5-HT1A receptors and its moderate antagonism of the 5-HT2 receptor. ${ }^{17,18)}$ Compared to adults, children and adolescents more frequently experience EPS, but dystonic reactions are still quite rare. ${ }^{19)}$ There are reports of acute dystonia following treatment with aripiprazole at doses of $10 \mathrm{mg} /$ day and above, ,7,20,21) and aripiprazole-induced acute dystonia, particularly cases of torticollis, has been shown to be more frequent in young males. ${ }^{22)}$ Furthermore, male gender, younger age, cocaine abuse, a history of dystonia, and use of high-potency neuroleptics are known risk factors for the development of dystonia. ${ }^{23)}$ The first patient in the present study was male and had risk factors in terms of his age and gender, but the second was female and younger than most other dystonia cases. Similar to other cases, the present patients developed torticollis within the first 3 days of aripiprazole treatment, but in contrast to most cases of dystonia that occurred after aripiprazole doses of $10 \mathrm{mg} /$ day and above, only the present cases 
and one other ${ }^{22)}$ developed dystonia after a dose of 5 $\mathrm{mg} /$ day.

The distinctive features of the present low-dose aripiprazole-induced dystonia cases were the prior use of atomoxetine for the treatment of ADHD and a recent history of drug discontinuation. Although various biological factors have been implicated in the etiology of ADHD, the dopaminergic hypothesis of this disorder is the most widely accepted understanding of ADHD pathophysiology. ${ }^{24)}$ ADHD is thought to be based in the dysregulation of dopaminergic neurotransmission, and a number of dopamine-related behavioral alterations have been identified in clinical cases and animal models. ${ }^{25)}$ Atomoxetine, which is a selective inhibitor of the noradrenaline transporter, can be used for the treatment of ADHD because it increases extracellular concentrations of noradrenaline and dopamine in the PFC. ${ }^{14)}$ A recent study found that atomoxetine treatment significantly increased dopamine concentrations in the PFC, striatum, and hypothalamus of spontaneously hypertensive rats (SHRs) and also caused downregulation of dopamine D2 receptor expression in a dose-dependent manner. ${ }^{26)}$

Aripiprazole is a partial agonist of the dopamine D2 receptor, and its action stabilizes this receptor system and plays a critical role in its unique clinical effects. ${ }^{27,28)}$ It has been postulated that functional selectivity can explain the pharmacological profile of aripiprazole. ${ }^{29)}$ Accumulated evidence from in vitro studies suggests that aripiprazole displays functional selectivity at the dopamine D2 receptor; it may act as a potent partial agonist, a weak agonist, or an antagonist depending on the targeted receptors. $^{28,29)}$ Accordingly, dopaminergic tone in the surrounding milieu is very important when determining the pharmacological profile of aripiprazole. ${ }^{13)}$ Taken together, these findings suggest that the dopamine system is the common point of action for aripiprazole and atomoxetine. From this perspective, it is possible to speculate that the moderately high doses of atomoxetine that were administered to the present patients increased dopamine concentrations in the PFC and striatum and resulted in the downregulation of D2 receptor expression. Furthermore, the abrupt cessation of atomoxetine and the immediate initiation of aripiprazole in this milieu may have resulted in aripiprazole acting as an antagonist at dopamine D2 receptors and causing unexpected EPS, even at a low dose. In their case report of aripiprazole-induced acute dystonia following the discontinuation of methylphenidate treatment, McLaren et al. ${ }^{11)}$ suggested that the abrupt reduction in synaptic dopamine levels after the discontinuation of methylphenidate decreased the number of dopamine D2 receptors and resulted in increased susceptibility to D2 receptor blockage. Although atomoxetine does not have a significant effect on dopamine levels in the nigrostriatal pathway, methylphenidate is known to increase dopaminergic action in this region. ${ }^{30)}$ Accordingly, atomoxetine does not aggravate tic disorders and may even reduce the severity of these symptoms. Nevertheless, novel-onset tic disorders and the deterioration of comorbid tics have been reported in some cases following atomoxetine treatment. The effect of atomoxetine on tics can be attributed to its indirect activity on dopamine levels in the striatal region. ${ }^{31,32)}$ Additionally, in an SHR animal model, atomoxetine increased dopamine concentrations while decreasing dopamine D2 receptor expression via downregulation in the striatum, $\mathrm{PFC}$, and hypothalamus in a dose-dependent manner. ${ }^{26)}$ In the present cases, the dystonia may have been caused by the indirect effects of atomoxetine on the striatal dopaminergic system, which, as explained by McLaren et al. ${ }^{11)}$, may have caused the dopamine D2 receptors to become susceptible to blockage and thereby resulted in dystonia. Therefore, the development of acute dystonia after low doses of atomoxetine ( 5 mg daily) may support the receptor susceptibility hypothesis. $^{11)}$

Another explanation for this phenomenon is related to action within the noradrenergic system. As previously mentioned, atomoxetine is a highly selective and potent inhibitor of the presynaptic noradrenaline transporter, and results in increased noradrenaline levels in the PFC. ${ }^{14,33)}$ Animal studies have shown that the increased activity of noradrenergic neurons is related to the development of dystonia. ${ }^{34)}$ Similarly, a clinical case report found that acute dystonia developed after a single dose of duloxetine, which inhibits the reuptake of noradrenaline, and it was suggested that the manifestation of these symptoms was due to alterations in the dopamine-noradrenaline balance that resulted in enhanced noradrenergic tone. Thus, dystonia may develop due to dopamine blockage or the relative hyperactivity of noradrenaline that can be caused by the enhanced release of noradrenaline, as in idiopathic dystonia cases. ${ }^{35)}$ In the present patients, atomoxetine may have altered the dopamine-noradrenaline balance by increasing noradrenergic activity, and as a result, low-dose aripiprazole could have caused dopamine blockage and resulted in acute dystonia. The immediate initiation of aripiprazole treatment after the abrupt cessation of atomoxetine treatment and the rapid development of the observed side effects were common to both patients, suggesting that the 
treatment environment of the patient plays an important role in the development of dystonia.

This particular side effect of low-dose aripiprazole can also be explained by drug metabolism. The CYP2D6 and CYP3A4 cytochrome enzyme systems are responsible for the metabolism of aripiprazole, ${ }^{18)}$ and high-dose atomoxetine inhibits CYP2D6, resulting in increased plasma levels of aripiprazole. ${ }^{36)}$ In the present cases, the levels of aripiprazole may have been enhanced due to the inhibition of CYP2D6 even though the dose of atomoxetine was relatively low. Additionally, atomoxetine metabolism occurs via the CYP2D6 enzyme system, and its being a substrate in same enzyme systems may have resulted in competitive inhibition and further increased the plasma levels of aripiprazole. However, this possibility could not be assessed in the present study because the plasma levels of aripiprazole were not measured.

To the best of our knowledge, this is the first study to report the development of acute dystonia after a treatment switch from atomoxetine to low-dose aripiprazole. In both of the present cases, aripiprazole treatment was initiated just after the abrupt cessation of atomoxetine treatment, and it is possible that the interactions among atomoxetine, aripiprazole, and individual risk factors contributed to this phenomenon. These cases emphasize the need for an awareness of the risk of acute dystonia when using low doses of aripiprazole, especially when switching to aripiprazole from drugs that affect the dopaminergic system. It is also important to consider the unique properties of each patient while being aware of the rare but possible side effects of antipsychotic drugs.

\section{REFERENCES}

1. Buckley PF. Aripiprazole: efficacy and tolerability profile of a novel-acting atypical antipsychotic. Drugs Today (Barc) 2003;39:145-151.

2. Stahl SM. Stahl's essential psychopharmacology: Neuroscientific basis and practical applications. 3rd ed. Cambridge, New York:Cambridge University Press,2008.

3. Han M, Huang XF, Deng C. Aripiprazole differentially affects mesolimbic and nigrostriatal dopaminergic transmission: implications for long-term drug efficacy and low extrapyramidal side-effects. Int $J$ Neuropsychopharmacol 2009; 12:941-952.

4. Marder SR, McQuade RD, Stock E, Kaplita S, Marcus R, Safferman AZ, et al. Aripiprazole in the treatment of schizophrenia: safety and tolerability in short-term, placebocontrolled trials. Schizophr Res 2003;61:123-136.

5. Fountoulakis KN, Siamouli M, Kantartzis S, Panagiotidis $P$, Iacovides A, Kaprinis GS. Acute dystonia with low-dosage aripiprazole in Tourette's disorder. Ann Pharmacother 2006;40:775-777.

6. Lim HK, Pae CU, Lee C, Lee CU. Tardive dystonic symptoms associated with aripiprazole treatment. Prog Neuro- psychopharmacol Biol Psychiatry 2008;32:589-590.

7. Varkula M, Dale R. Acute dystonic reaction after initiating aripiprazole monotherapy in a 20-year-old man. J Clin Psychopharmacol 2008;28:245-247.

8. Greenaway M, Elbe D. Focus on aripiprazole: a review of its use in child and adolescent psychiatry. $J$ Can Acad Child Adolesc Psychiatry 2009;18:250-260.

9. Blankenship K, Erickson CA, Stigler KA, Posey DJ, McDougle CJ. Aripiprazole for irritability associated with autistic disorder in children and adolescents aged 6-17 years. Ped Health 2010;4:375-381.

10. Findling RL, Kauffman RE, Sallee FR, Carson WH, Nyilas M, Mallikaarjun S, et al. Tolerability and pharmacokinetics of aripiprazole in children and adolescents with psychiatric disorders: an open-label, dose-escalation study. J Clin Psychopharmacol 2008;28:441-446.

11. McLaren JL, Cauble S, Barnett RJ. Aripiprazole induced acute dystonia after discontinuation of a stimulant medication. J Clin Psychopharmacol 2010;30:77-78.

12. Ono S, Suzuki Y, Shindo M, Endo T, Fukui N, Sugai T, et al. Improvement of tardive dyskinesia and dystonia associated with aripiprazole following a switch to quetiapine: case report and review of the literature. J Clin Pharm Ther 2012;37:370-372.

13. Iñiguez $\mathrm{SD}$, Cortez $\mathrm{AM}$, Crawford $\mathrm{CA}, \mathrm{McD}$ ougall SA. Effects of aripiprazole and terguride on dopamine synthesis in the dorsal striatum and medial prefrontal cortex of preweanling rats. J Neural Transm (Vienna) 2008;115:97-106.

14. Bymaster FP, Katner JS, Nelson DL, Hemrick-Luecke SK, Threlkeld PG, Heiligenstein JH, et al. Atomoxetine increases extracellular levels of norepinephrine and dopamine in prefrontal cortex of rat: a potential mechanism for efficacy in attention deficit/hyperactivity disorder. Neuropsychopharmacology 2002;27:699-711.

15. American Psychiatric Association. Diagnostic and statistical manual of mental disorders: DSM-IV-TR. 4th ed. Washington, DC:American Psychiatric Association;2000.

16. Naranjo CA, Busto U, Sellers EM, Sandor P, Ruiz I, Roberts EA, et al. A method for estimating the probability of adverse drug reactions. Clin Pharmacol Ther 1981;30:239-245.

17. Mamo D, Graff A, Mizrahi R, Shammi CM, Romeyer F, Kapur S. Differential effects of aripiprazole on D(2), 5-HT(2), and 5-HT(1A) receptor occupancy in patients with schizophrenia: a triple tracer PET study. Am J Psychiatry 2007;164:1411-1417.

18. Soygür H. Pharmacokinetic and pharmacodynamic characteristics of aripiprazole. Bull Clin Psychopharmacol 2008; 18 Suppl 1:1-6.

19. Bristol-Myers Squibb Company/Otsuka America Pharmaceutical Inc. Aripiprazole (Abilify) prescribing information. Princeton, NJ:Bristol-Myers Squibb Co and Otsuka America Pharmaceutical, Inc;2006.

20. Chen MH, Liou YJ. Aripiprazole-associated acute dystonia, akathisia, and parkinsonism in a patient with bipolar I disorder. J Clin Psychopharmacol 2013;33:269-270.

21. Goga JK, Seidel L, Walters JK, Khushalani S, Kaplan D. Acute laryngeal dystonia associated with aripiprazole. $J$ Clin Psychopharmacol 2012;32:837-839.

22. Ittasakul P, Srivastava S, Hiranyatheb T, Ketter TA. Torticollis after low-dose aripiprazole administration in a Thai schizophrenia patient. Asian J Psychiatr 2012;5:365-366.

23. van Harten PN, Hoek HW, Kahn RS. Acute dystonia induced by drug treatment. BMJ 1999;319:623-626.

24. Genro JP, Kieling C, Rohde LA, Hutz MH. Attentiondeficit/hyperactivity disorder and the dopaminergic hypoth- 
eses. Expert Rev Neurother 2010;10:587-601.

25. Prediger RD, Pamplona FA, Fernandes D, Takahashi RN. Caffeine improves spatial learning deficits in an animal model of attention deficit hyperactivity disorder (ADHD) -the spontaneously hypertensive rat (SHR). Int $J$ Neuropsychopharmacol 2005;8:583-594.

26. Moon SJ, Kim CJ, Lee YJ, Hong M, Han J, Bahn GH. Effect of atomoxetine on hyperactivity in an animal model of attention-deficit/hyperactivity disorder (ADHD). PLoS One 2014;9:e108918.

27. Hirose T, Kikuchi T. Aripiprazole, a novel antipsychotic agent: dopamine D2 receptor partial agonist. J Med Invest 2005;52 Suppl:284-290.

28. Burris KD, Molski TF, Xu C, Ryan E, Tottori K, Kikuchi $\mathrm{T}$, et al. Aripiprazole, a novel antipsychotic, is a highaffinity partial agonist at human dopamine D2 receptors. $J$ Pharmacol Exp Ther 2002;302:381-389.

29. Mailman RB, Murthy V. Third generation antipsychotic drugs: partial agonism or receptor functional selectivity? Curr Pharm Des 2010;16:488-501.

30. Del Campo N, Chamberlain SR, Sahakian BJ, Robbins TW. The roles of dopamine and noradrenaline in the path- ophysiology and treatment of attention-deficit/hyperactivity disorder. Biol Psychiatry 2011;69:e145-e157.

31. Párraga HC, Párraga MI, Harris DK. Tic exacerbation and precipitation during atomoxetine treatment in two children with attention-deficit hyperactivity disorder. Int J Psychiatry Med 2007;37:415-424.

32. Ledbetter M. Atomoxetine use associated with onset of a motor tic. J Child Adolesc Psychopharmacol 2005;15:331333.

33. Garnock-Jones KP, Keating GM. Atomoxetine: a review of its use in attention-deficit hyperactivity disorder in children and adolescents. Paediatr Drugs 2009;11:203-226.

34. Raike RS, Jinnah HA, Hess EJ. Animal models of generalized dystonia. NeuroRx 2005;2:504-512.

35. Karakaş Uğurlu G, Onen S, Bayındırlı D, Cayköylü A. Acute dystonia after using single dose duloxetine: case report. Psychiatry Investig 2013;10:95-97.

36. Sauer JM, Long AJ, Ring B, Gillespie JS, Sanburn NP, DeSante KA, et al. Atomoxetine hydrochloride: clinical drug-drug interaction prediction and outcome. J Pharmacol Exp Ther 2004;308:410-418. 